\title{
PERANCANGAN APLIKASI SERVIS HANDPHONE BERBASIS WEB PADA CENTRA PHONE BANJARMASIN
}

\author{
Fauzi Yusa Rahman ${ }^{1)}$, Zayid Musiafa ${ }^{2)}$, Kholik Setiawan ${ }^{3)}$ \\ ${ }^{1)}$ Fakultas Teknologi Informasi, Universitas Islam Kalimantan MAB Banjarmasin \\ email: fauziyusarahman@gmail.com \\ ${ }^{2)}$ Fakultas Teknologi Informasi, Universitas Islam Kalimantan MAB Banjarmasin \\ email: zayidmusiafa@fti.uniska-bjm.ac.id \\ ${ }^{3)}$ Fakultas Teknologi Informasi, Universitas Islam Kalimantan MAB Banjarmasin \\ email: kholiksetiawanfti@gmail.com
}

\begin{abstract}
Abstrak
Centra phone merupakan toko handphone yang bergerak pada pelayanan servis handphone dengan berbagai merk dan tipe handphone yang memiliki banyak perbedaan, pada toko ini menerima berbagai macam jenis perbaikan pada peralatan handphone baik perbaikan dari perangkat keras ataupun perbaikan dari perangkat lunak. Pada saat ini pengelolaan data servis handphone masih bersifat manual, yaitu pelanggan datang untuk memperbaiki handphonenya, kemudian data pelanggan dicatat pada nota. Hal ini tentu saja memiliki berbagai macam kekurangan, yaitu data servis yang berupa nota mungkin saja hilang atau rusak, bahkan kesulitan bagi teknisi yaitu bagaimana mengingat data pelanggan dan data kerusakan handphone yang telah lalu, karna tidak adanya media penyimpanan yang baik. Oleh karena itu peneliti akan membuat sebuah aplikasi berbasis web yang akan menyimpan semua data pelanggan yang memperbaiki handphone, data kerusakan pada handphone dan data perbaikan yang dilakukan. Perancangan aplikasi servis handphone menggunakan metode waterfall sering dinamakan siklus hidup klasik (classic life cycle), pada metode ini menggambarkan pendekatan yang sistematis dan juga berurutan pada pengembangan perangkat lunak, dimulai dengan spesifikasi kebutuhan pengguna lalu berlanjut melalui tahapan perencanaan (planning), permodelan (modeling), konstruksi (construction), serta penyerahan sistem ke para pelanggan/pengguna (deployment), yang diakhiri dengan dukungan pada perangkat lunak lengkap yang dihasilkan.
\end{abstract}

Kata kunci: aplikasi, web, centra phone, servis handphone

\section{PENDAHULUAN}

Pesatnya perkembangan bisnis yang mengadaptasi dari teknologi informasi dan komunikasi, mendorong terjadinya persaingan bisnis. Setiap pelaku bisnis bersaing untuk mencari dan meraih pelanggan agar menggunakan produk atau jasa dari perusahaan mereka. Kebutuhan manusia akan kegunaan handphone pada saat ini sangatlah penting, oleh karena itu hampir setiap orang mempunyai handphone untuk memaksimalkan pekerjaannya dalam melakukan komunikasi. Pada setiap teknologi pasti terdapat kekurangan, yaitu teknologi tersebut bisa rusak atau tidak berfungsi secara baik karena kualitas dari handphone yang digunakan maupun karena kesalahan penggunaan individunya. Oleh karena servis handphone sangat dibutuhkan dalam kondisi seperti ini.
Centra phone merupakan toko handphone yang bergerak pada servis handphone dengan berbagai merk dan tipe handphone yang memiliki banyak perbedaan, pada toko ini menerima berbagai macam jenis perbaikan pada peralatan handphone baik perbaikan dari perangkat keras ataupun perbaikan dari perangkat lunak. Pada saat ini pengelolaan data servis handphone masih bersifat manual, yaitu pelanggan datang untuk memperbaiki handphonenya, kemudian data pelanggan dicatat pada nota, nota tersebut terdiri dari dua lembar yaitu lembar warna putih dan lembar warna merah. Nota dengan lembar merah di bawa oleh pelanggan, sedangkan lembar putih disimpan di toko. Apabila perbaikan sudah selesai dilakukan maka pelanggan harus menunjukkan nota merah untuk mengambil handphone yang sudah selesai di servis. 
Hal ini tentu saja memiliki berbagai macam kekurangan, yaitu data servis yang berupa nota tentu saja akan dapat hilang atau rusak, bahkan kesulitan bagi teknisi yaitu bagaimana mengingat data pelanggan dan data kerusakan handphone yang telah lalu, karna tidak adanya media penyimpanan yang baik. Oleh karena itu peneliti akan membuat sebuah aplikasi berbasis web yang akan menyimpan semua data pelanggan yang memperbaiki handphone, data kerusakan pada handphone dan data perbaikan yang dilakukan.

\section{METODE PENELITIAN}

Perancangan aplikasi servis handphone menggunakan metode waterfall sering dinamakan siklus hidup klasik (classic life cycle), pada metode ini menggambarkan pendekatan yang sistematis dan juga berurutan pada pengembangan perangkat lunak, dimulai dengan spesifikasi kebutuhan pengguna lalu berlanjut melalui tahapan perencanaan (planning), permodelan (modeling), konstruksi (construction), serta penyerahan sistem ke para pelanggan/pengguna (deployment), yang diakhiri dengan dukungan pada perangkat lunak lengkap yang akan dihasilkan.

Pengembangan metode waterfall memiliki beberapa tahapan yang berurut yaitu: requirement (analisis kebutuhan), design system (desain sistem), coding (pengkodean) dan testing (pengujian), operation (penerapan program), dan maintenance (pemeliharaan).

Dalam pengembangan sistem ini, terdapat beberapa tahapan yang harus dilakukan, adapun tahapan tersebut adalah sebagai berikut:

a. Requirement Analisis

Tahap ini pengembang sistem diperlukan komunikasi yang bertujuan untuk memahami perangkat lunak yang diharapkan oleh pengguna dan batasan perangkat lunak tersebut. Informasi ini biasanya dapat diperoleh melalui wawancara, diskusi atau survei langsung. Informasi dianalisis untuk mendapatkan data yang dibutuhkan oleh pengguna.

b. System Design

Spesifikasi kebutuhan dari tahap sebelumnya akan dipelajari dalam fase ini dan desain sistem disiapkan. Desain Sistem membantu dalam menentukan perangkat keras(hardware) dan sistem persyaratan dan juga membantu dalam mendefinisikan arsitektur sistem secara keseluruhan.

c. Implementation

Pada tahap ini, sistem pertama kali dikembangkan di program kecil yang disebut unit, yang terintegrasi dalam tahap selanjutnya. Setiap unit dikembangkan dan diuji untuk fungsionalitas yang disebut sebagai unit testing.

d. Integration \& Testing

Seluruh unit yang dikembangkan dalam tahap implementasi diintegrasikan ke dalam sistem setelah pengujian yang dilakukan masing-masing unit. Setelah integrasi seluruh sistem diuji untuk mengecek setiap kegagalan maupun kesalahan.

e. Operation \& Maintenance

Tahap akhir dalam model waterfall. Perangkat lunak yang sudah jadi, dijalankan serta dilakukan pemeliharaan. Pemeliharaan termasuk dalam memperbaiki kesalahan yang tidak ditemukan pada langkah sebelumnya. Perbaikan implementasi unit sistem dan peningkatan jasa sistem sebagai kebutuhan baru.

\subsection{Analisa Sistem}

Dalam membangun aplikasi diperlukan perencanaan agar dihasilkan sistem yang dapat berjalan optimal. Tahap perencanaan ini terbagi atas:

a. Menentukan tujuan pembuatan aplikasi

Tujuan penelitian ini adalah agar memberikan kemudahan baik bagi pemilik toko, teknisi maupun pelanggan untuk melakukan proses serah terima barang, deteksi kerusakan, maupun proses pencarian data pelanggan secara cepat dan mudah.

b. Menentukan siapa yang akan menjadi pemakai

Aplikasi data servis handphone ini digunakan oleh administrator, kemudian dilanjutakan oleh teknisi yang melakukan perbaikan dan terakhir pemilik toko untuk melihat data laporan.

\subsection{Perancangan Sistem}

Proses perancangan diperlukan untuk pembuatan aplikasi yang baik. Perancangan sistem secara terperinci, dilakukan dengan cara: 
a. Rancangan Menu

b. Rancangan Database

c. Relasi Tabel

d. Diagram Konteks

e. Rancangan Tampilan

f. Rancangan Output dan Laporan

g. Pembuatan Program

Pembuatan data servis handphone ini dibuat menggunakan bahasa pemrograman PHP dan MySQL sebagai pengelola databasenya.

\subsection{Testing Aplikasi}

Pada tahap ini, dilakukan uji terhadap sistem yang telah selesai dibuat dengan menggunakan modem dan satu buah laptop server, setiap proses pendataan dilakukan langsung pada hosting dan domain yang telah disediakan sebelumnya.

\section{HASIL DAN PEMBAHASAN}

Aplikasi servis handphone terdiri dari tiga level pengguna, yaitu administrator, teknisi, dan pemilik. Aplikasi servis handphone bisa di pakai secara offline maupun online.

\subsection{Rancangan Menu}

Rancangan menu pada aplikasi data servis handphone terdiri atas 3 level pengguna. Berikut rancangan menu yang terbentuk:

1. Menu Level Administrator
a. Login
b. Beranda
c. Modul
d. Pengguna
e. Merk Handphone
f. Perbaikan Proses
g. Perbaikan Selesai
h. Perbaikan Diambil
i. Perbaikan Batal
j. Laporan
k. Tentang
1. Keluar

2. Menu Level Teknisi
a. Login
b. Beranda
c. Merk Handphone
d. Perbaikan Proses
e. Perbaikan Selesai
f. Perbaikan Diambil
g. Perbaikan Batal
h. Laporan

i. Tentang

j. Keluar

3. Menu Level Pemilik
a. Login
b. Beranda
c. Laporan
d. Tentang
e. Keluar

\subsection{Rancangan Basis Data}

Rancangan basis data digunakan untuk mengidentifikasi kebutuhan tabel yang diperlukan oleh sistem. Perancangan basis data pada aplikasi servise handphone dibuat menggunakan database MySQL pada aplikasi PHPMyAdmin dan diberi nama dbcphone, berikut tabel-tabel yang terbentuk:

1. Tabel Modul

2. Tabel Pengguna

3. Tabel Merk

4. Tabel Perbaikan

\subsection{Relasi Tabel}

Relasi antar tabel digunakan untuk melihat tabel-tabel mana saja yang terhubung. Berikut relasi antar tabel yang terbentuk:

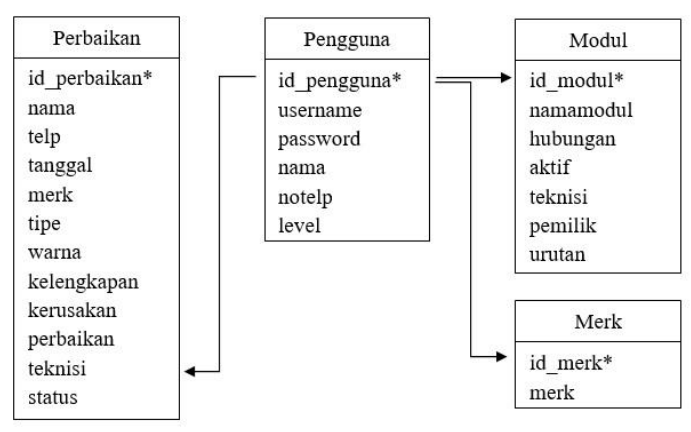

Gambar 1. Relasi Tabel

\subsection{Diagram Konteks}

Diagram konteks digunakan untuk melihat proses sistem, dari mana dan kemana . Berikut rancangan diagram konteks yang terbentuk dalam aplikasi servis handphone:

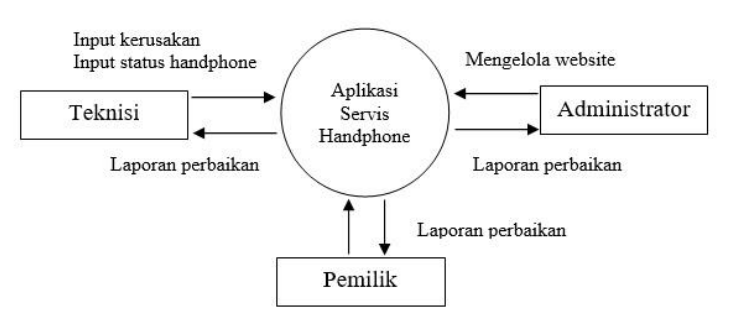


Gambar 2. Diagram Konteks

\subsection{Rancangan Tampilan}

Rancangan tampilan merupakan hasil dari aplikasi servise handphone yang sudah di buat, berikut tampilan berdasarkan level pengguna:

1. Tampilan Level Administrator

a. Login

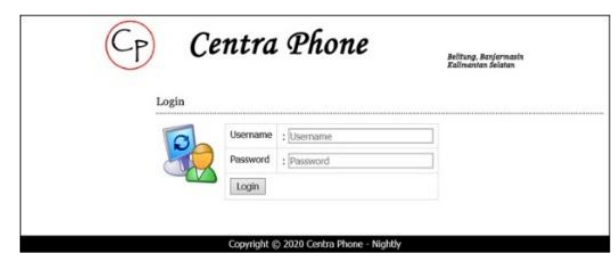

Gambar 3. Tampilan Login Level Administrator

b. Tampilan Beranda

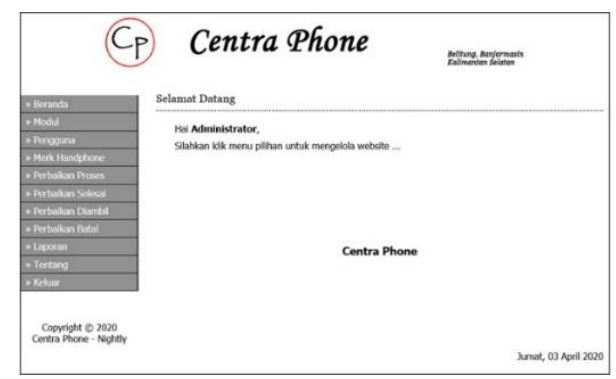

Gambar 4. Tampilan Beranda Level Administrator

c. Tampilan Modul

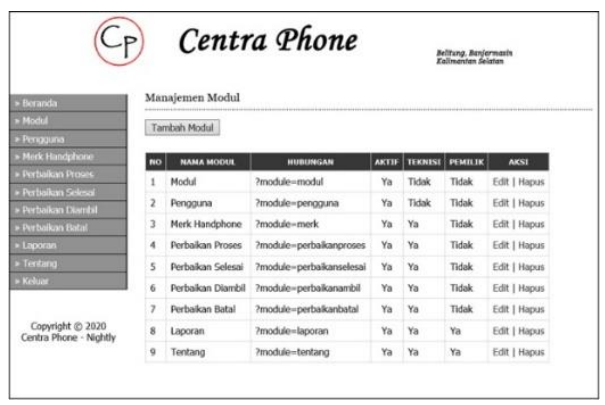

Gambar 5. Tampilan Modul Level Administrator

d. Tampilan Pengguna

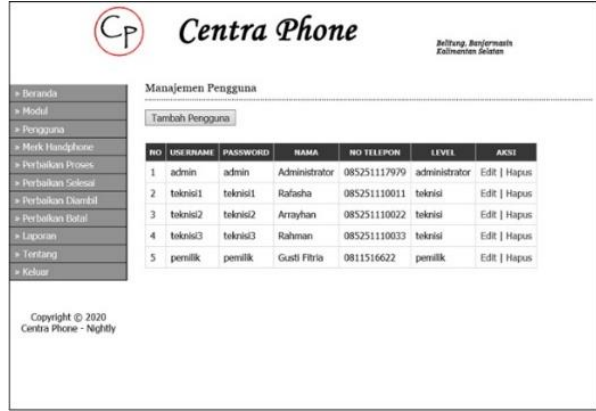

Gambar 6. Tampilan Pengguna Level Administrator

e. Tampilan Merk Handphone

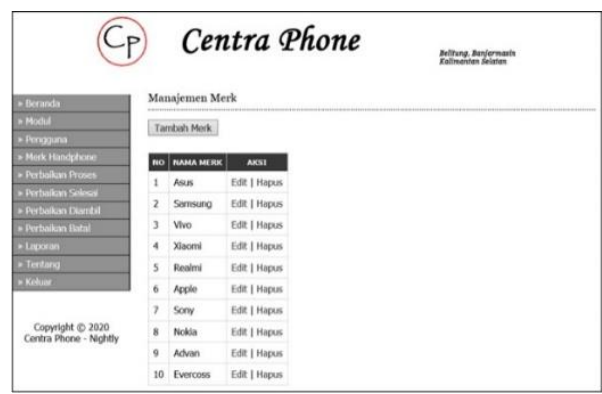

Gambar 7. Tampilan Merk Handphone Level Administrator

f. Tampilan Perbaikan Proses

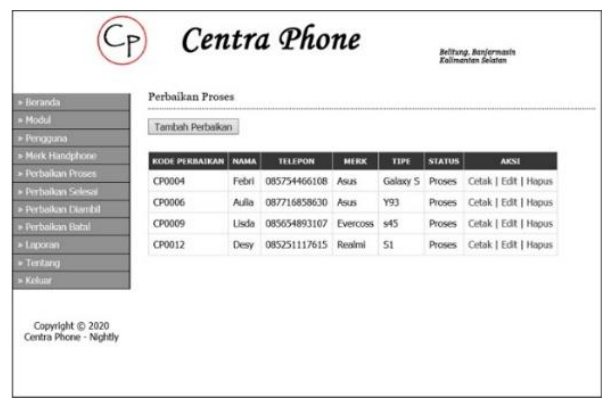

Gambar 8. Tampilan Perbaikan Proses Level Administrator

g. Tampilan Perbaikan Selesai

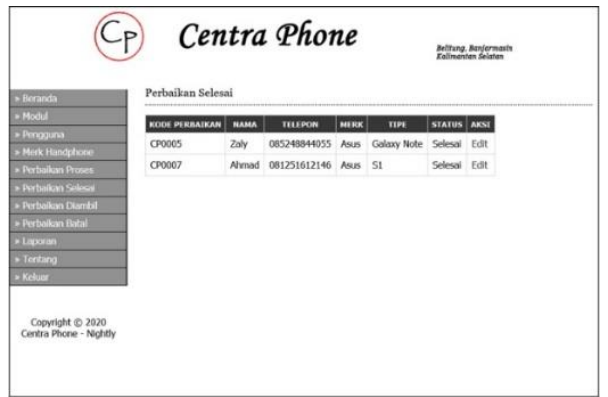

Gambar 9. Tampilan Perbaikan Selesai Level Administrator 
h. Tampilan Perbaikan Diambil

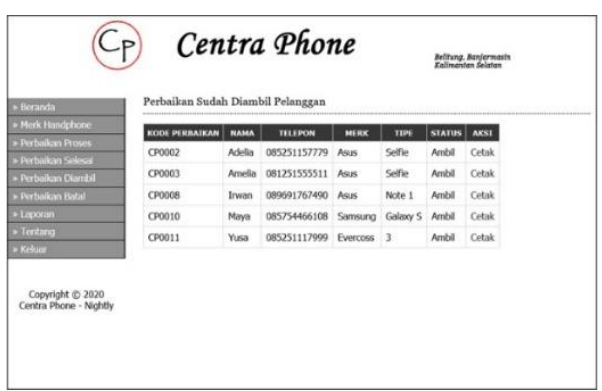

Gambar 10. Tampilan Perbaikan Diambil Level Administrator

i. Tampilan Perbaikan Batal

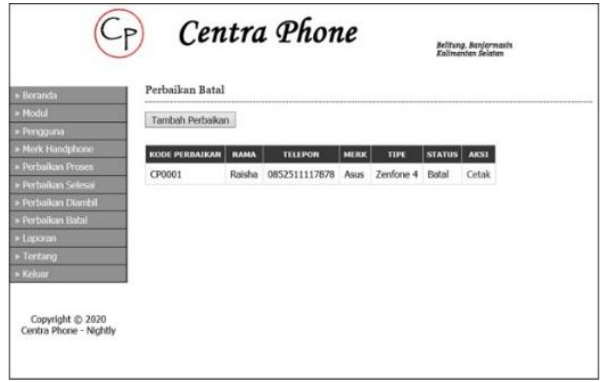

Gambar 11. Tampilan Perbaikan Batal Level Administrator

j. Tampilan Laporan

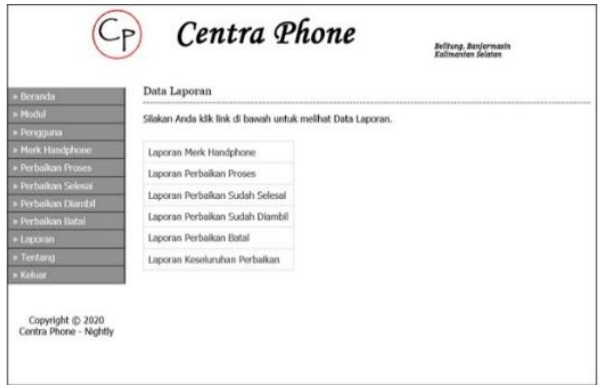

Gambar 12. Tampilan Laporan Level Administrator

k. Tampilan Tentang

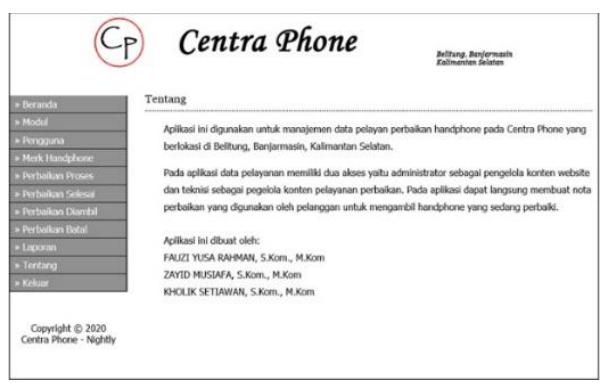

Gambar 13. Tampilan Tentang Level Administrator

2. Tampilan Level Teknisi

a. Tampilan Login

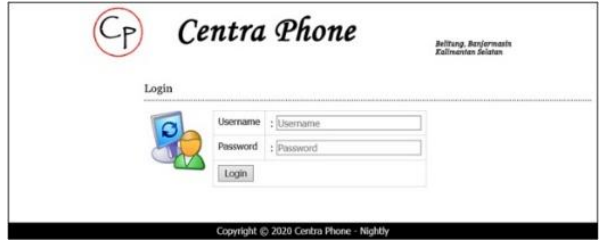

Gambar 14. Tampilan Login Level Teknisi

b. Tampilan Beranda

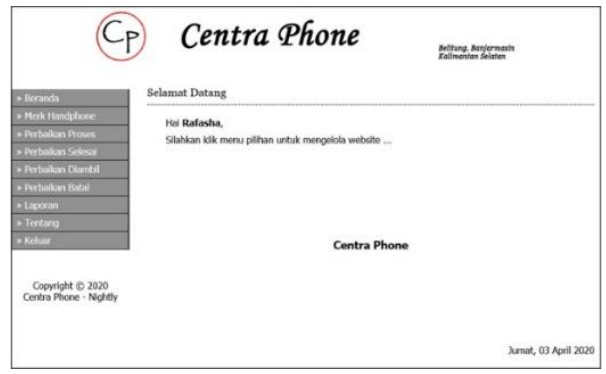

Gambar 15. Tampilan Beranda Level Teknisi

c. Tampilan Merk Handphone

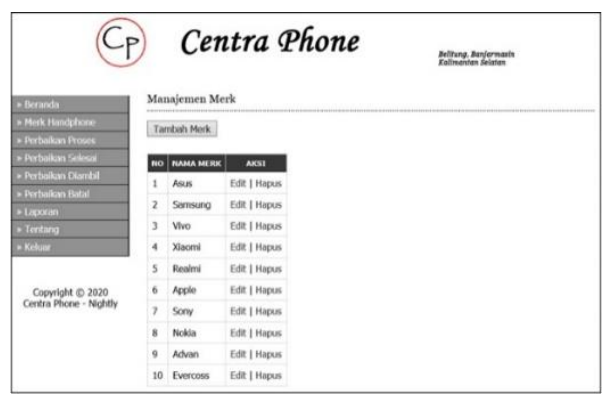

Gambar 16. Tampilan Merk Handphone Level Teknisi

d. Tampilan Perbaikan Proses

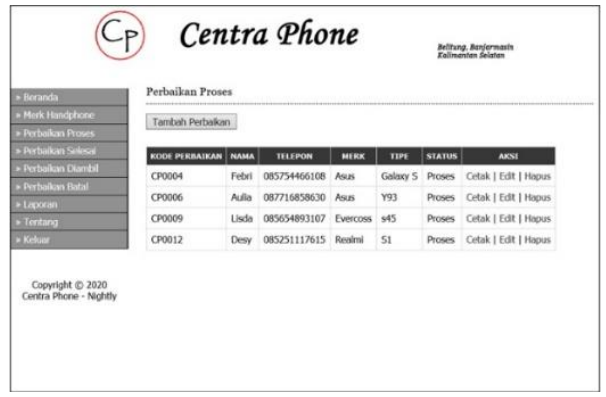

Gambar 17. Tampilan Perbaikan Proses Level Teknisi

e. Tampilan Perbaikan Selesai 


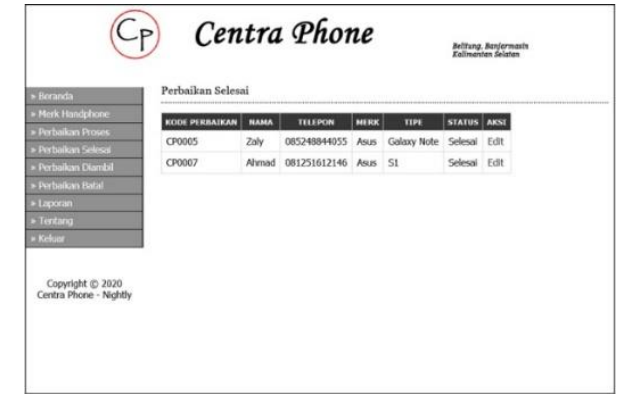

Gambar 18. Tampilan Perbaikan Selesai Level Teknisi

f. Tampilan Perbaikan Diambil

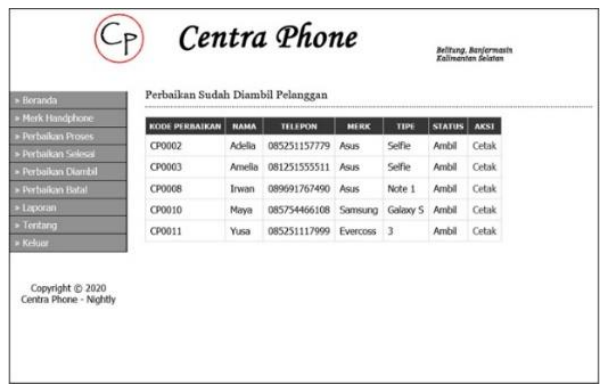

Gambar 19. Tampilan Perbaikan Diambil Level Teknisi

g. Tampilan Perbaikan Batal

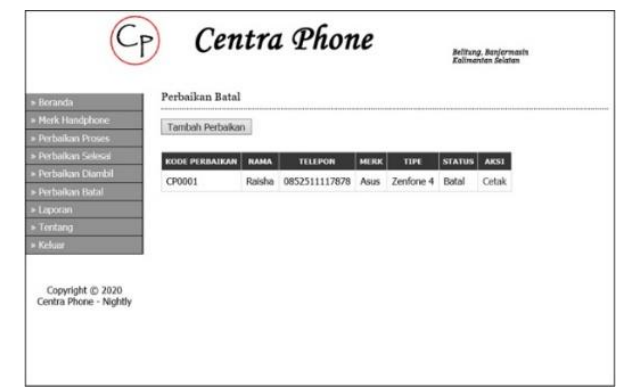

Gambar 20. Tampilan Perbaikan Batal Level Teknisi

h. Tampilan Laporan

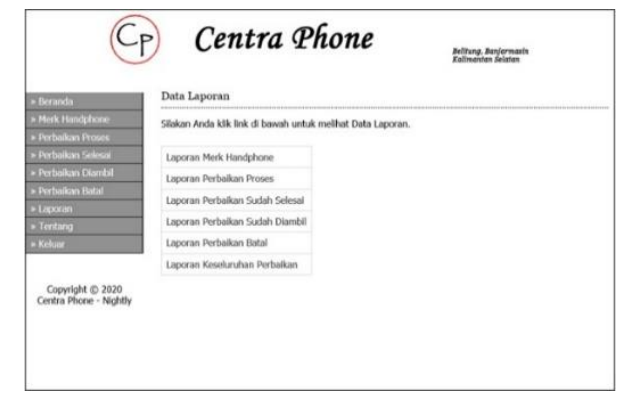

Gambar 21. Tampilan Laporan Level Teknisi

i. Tampilan Tentang

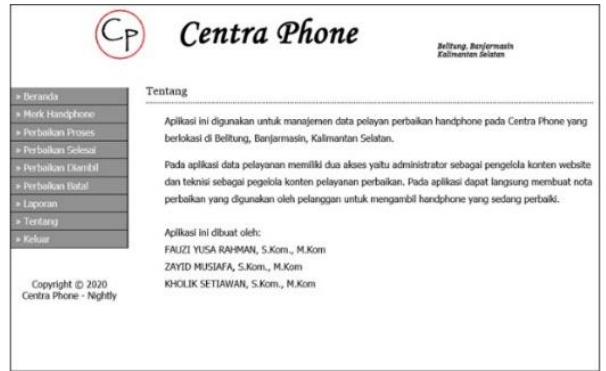

Gambar 22. Tampilan Tentang Level Teknisi

3. Tampilan Level Pemilik

a. Tampilan Login

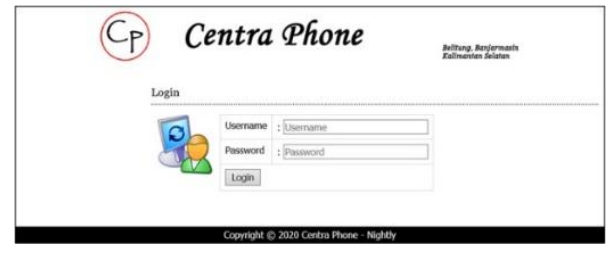

Gambar 23. Tampilan Login Level Pemilik

b. Tampilan Beranda

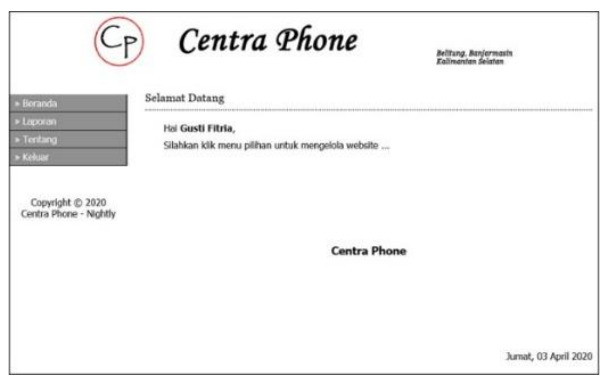

Gambar 24. Tampilan Beranda Level Pemilik

c. Tampilan Laporan

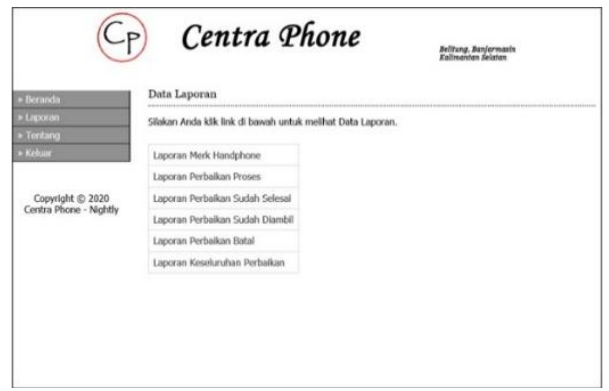

Gambar 25. Tampilan Laporan Level Pemilik

d. Tampilan Tentang 


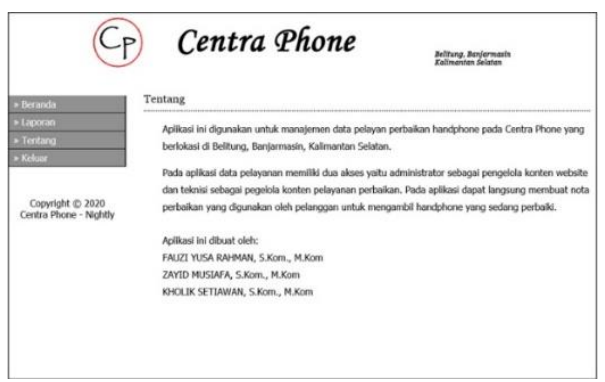

Gambar 26. Tampilan Tentang Level Pemilik

\subsection{Rancangan Laporan}

Rancangan laporan merupakan hasil dari aplikasi servise handphone yang sudah di buat, berikut ranvangan laporan yang bisa dibuat:

\section{Laporan Nota Perbaikan}

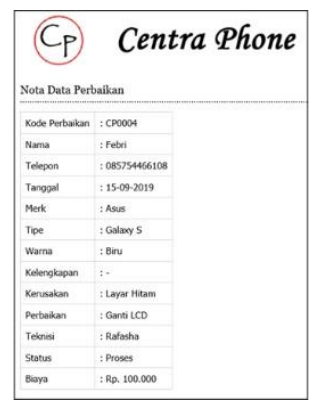

Gambar 27. Laporan Nota Perbaikan

2. Laporan Merk Handphone

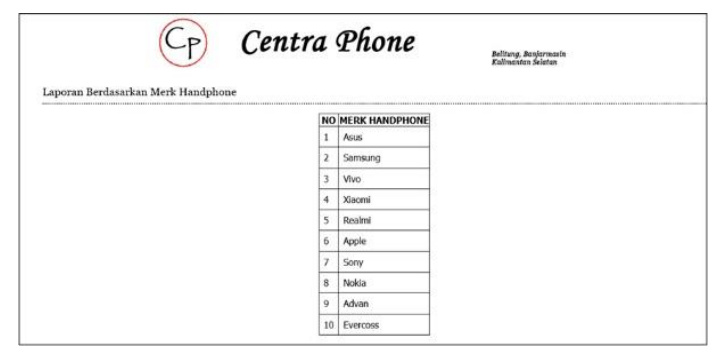

Gambar 28. Laporan Merk Handphone

3. Laporan Berdasarkan Handphone Masih Proses

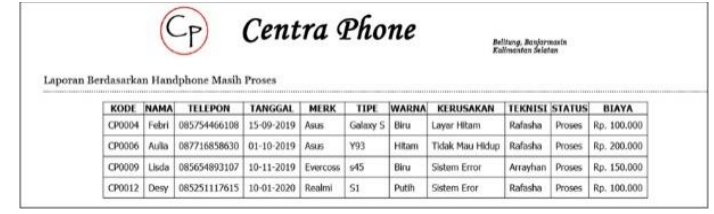

Gambar 29. Laporan Berdasarkan Handphone Masih Proses

4. Laporan Berdasarkan Handphone Sudah Selesai

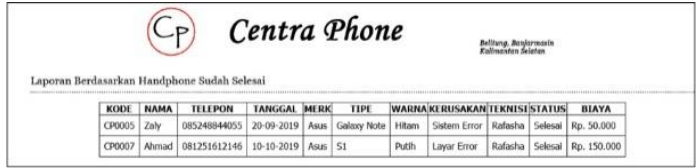

Gambar 30. Laporan Berdasarkan Handphone Sudah Selesai

5. Laporan Berdasarkan Handphone Sudah Diambil

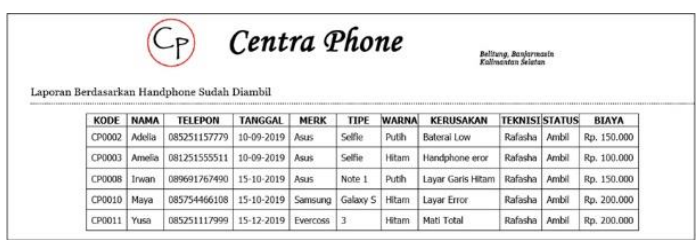

Gambar 31. Laporan Berdasarkan Handphone sudah Diambil

6. Laporan Berdasarkan Handphone Batal Servise

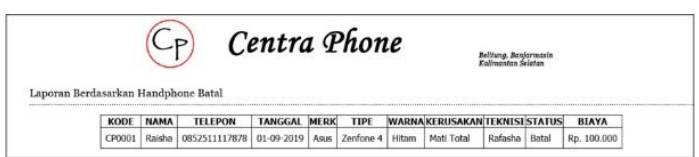

Gambar 32. Laporan Berdasarkan Handphone Batal Servise

7. Laporan Berdasarkan Handphone Keseluruhan

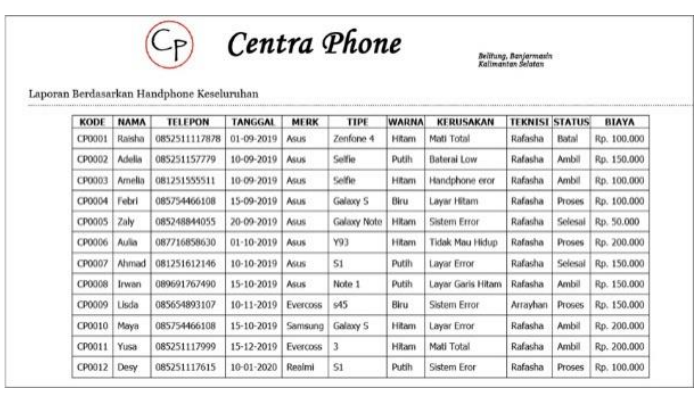

Gambar 33. Laporan Berdasarkan Handphone Keseluruhan

\section{KESIMPULAN}

Penelitian dilakukan pada Centra Phone yang beralamat di jalan Belitug, Banjarmasin, Kalimantan Selatan. Centra Phone melayani jasa servis handphone baik itu perbaikan dari peragkat lunak atau peragkat keras. Metode waterfall sering dinamakan siklus hidup klasik (classic life cycle) menggambarkan pendekatan yang sistematis dan juga berurutan pada pengembangan perangkat lunak, dimulai dengan spesifikasi kebutuhan pengguna lalu berlanjut melalui tahapan-tahapan perencanaan 
(planning), permodelan (modeling), konstruksi (construction), serta penyerahan sistem ke pengguna (deployment), yang diakhiri dengan dukungan pada perangkat lunak lengkap yang dihasilkan.

Tujuan penelitian ini adalah agar memberikan kemudahan baik administrator, teknisi, pemilik toko maupun pelanggan untuk melakukan proses serah terima barang, maupun proses pencarian data pelanggan secara cepat dan mudah. Aplikasi servise handphone dikelola oleh administrator, kemudian dilanjutakan oleh teknisi untuk mengelola dara servise dan terakhir pemilik toko untuk melihat data laporan. Aplikasi servise handphone ini dibuat menggunakan bahasa pemrograman PHP dan MySQL sebagai pengelola basis datanya. Penggunaan aplikasi sangat memudahkan untuk mendata semua data servis dan menyimpan nota servis apabila sewaktu-waktu dibutuhkan.

\section{DAFTAR PUSTAKA}

[1] Fatta, A., \& Hanif. (2007). Analisis \& Perancangan Sistem Informasi Untuk Keunggulan Bersaing perusahaan Organisasi Modern. Yogyakarta: ANDI.

[2] Hakim, Z. (2012, Agustus 16). Apa Itu Pemrograman Web? Retrieved Juli 2017, 2017, from Pemrograman Web: http://www.zainalhakim.web.id/posting/a pa-itu-pemrograman-web.html

[3] Peranginangin, K. (2006). Aplikasi WEB dengan PHP dan MySQL. Yogyakarta: ANDI.

[4] Sunyoto, A. (2007). Pemrograman Database dengan Visual Basic dan Microsoft SQL. Yogyakarta: ANDI.

[5] Utami, E. (2005). Konsep Dasar Pengolahan dan Pemrograman Database dengan SQ1 Server, Ms. Access, dan Ms. Visual Basic. Yogyakarta: ANDI.

[6] Wikipedia. (2019, September 7). HTML. Retrieved Oktober 1, 2019, from Wikipedia: https://id.wikipedia.org/wiki/HTML

[7] Wikipedia. (2019, Oktober 1). MySQL. Retrieved from Wikipedia: https://id.wikipedia.org/wiki/MySQL

[8] Wikipedia. (2019, September 20). PHP. Retrieved Oktober 1, 2019, from
Wikipedia:

https://id.wikipedia.org/wiki/PHP 